\title{
Bayesian Inference of Genetic Parameters for Survival, Flowering, Fruit Set, and Ripening in a Germplasm Collection of Chilean Strawberry Using Threshold Models
}

\author{
Freddy Mora \\ Instituto de Ciencias Biológicas, Universidad de Talca, Talca, Casilla 747, Chile \\ Cristóbal M. Concha \\ Facultad de Ciencias Forestales, Universidad de Concepción, Concepción, Casilla 160-C, Chile \\ Carlos R. Figueroa ${ }^{1}$ \\ Instituto de Ciencias Biológicas, Universidad de Talca, Talca, Casilla 747, Chile

\begin{abstract}
ADDITIONAL InDEX wORDs. Fragaria chiloensis, wild and domesticated clones, binary traits, clonal genetic gain, heritability, Gibbs sampling

Abstract. Fragaria chiloensis has a fruit with an excellent organoleptic quality and it is one of the parents of the commercially cultivated strawberry (Fragaria $\times$ ananassa), which supports the importance of characterization available germplasm to support further breeding. A genetic evaluation using a Bayesian analysis of genetic parameters for survival, flowering, fruit set, and ripening was carried out in 8 domesticated and 55 wild clones, covering most of the natural geographic range of this species in Chile. The Bayesian approach was performed using the Gibbs sampling algorithm. Threshold models were fitted to phenotypic data, as these traits were treated as binary variables. Plant survival rates in seasons 2013 and 2014 ranged from $0 \%$ to $85 \%$. According to the Bayesian analysis, the studied traits were found to be weak to moderately heritable ranging from broad-sense heritability $\left(\hat{H}^{2}\right)=14 \%$ (survival) to $=40 \%$ (fruit set). Survival and fruit set had the lowest $(17.9 \%)$ and highest $(34.9 \%)$ clonal genetic gain, which concurs with the lowest and highest values of $\hat{\boldsymbol{H}}^{2}$, respectively. The results of this preliminary study confirms the potential for selective breeding of $F$. chiloensis, given that five clones, including domesticated and wild, were simultaneously selected for all traits studied.
\end{abstract}

The chilean strawberry ( $F$. chiloensis ssp. chiloensis $\mathrm{f}$. chiloensis), one of the ancestral parents of the cultivated strawberry and domesticated by the native Mapuche, is cultivated in southern Chile in small-scale fields by a few farmers, mostly located in the Nahuelbuta mountain range (lat. $38^{\circ} \mathrm{S}$ ) (Finn et al., 2013; Hancock et al., 1999). This native berry has become a model for the study of fruit ripening (Cherian et al., 2014), and moreover has the potential to become a new gourmet berry due to its excellent organoleptic quality (Retamales et al., 2005). However, there are still limitations for its successful development as a commercial crop due to the lack of improved cultivars. In this way, a breeding program could help to develop cultivars with higher yields, improved fruit quality, and superior postharvest life (Retamales et al., 2005). To maximize fruit yield in $F$. chiloensis, the correct selection of specific clones adapted to environmental conditions is critical to obtain superior performance. Fragaria chiloensis breeding programs should aim to prioritize maximum fruit yield, together with high rates of fruit set and plant survival. Subsequently, plant survival in early stages of a breeding program must be one of the most important traits under study (Ballesta et al., 2015; Russo et al., 2007). This species often suffers from low field survival rates due to lack of

Received for publication 29 Oct. 2015. Accepted for publication 29 Mar. 2016. We acknowledge the financial support by the CONICYT, PIA/ACT-1110 (Chile).

${ }^{1}$ Corresponding author. E-mail: cfigueroa@utalca.cl. modern agricultural management practices, poor sanitary status of available planting material, and low frequency of renewal of plant material, which contributes to low yields. Double planting has been necessary to mitigate this effect which requires extra time and resources (Coyle et al., 2006). Therefore, the identification of phenotypes with high survival rates is a key factor to start a $F$. chiloensis breeding program.

From a statistical point of view, the traits such as survival and flowering have a Bernoulli distribution, with two possible categorical values (Mora and Serra, 2014; Santos et al., 2011). Threshold models have been reported to be useful for the genetic evaluation of categorical traits (Sorensen et al., 1994), enabling the estimation of genetic parameters, including heritability and genetic correlations (Mora and Saavedra, 2012). Earliness in fruit crops can be treated as a binary response (Mora et al., 2008), as there are many "zero" values as a result from many individuals not blooming at an early age. As a possible consequence, the assumption of normality of the response variable may be completely unrealistic. In this sense, a breeder would like to be able to predict whether a genotype has early production under specific environmental conditions or not. Several studies have applied Bayesian analysis for parameter estimation from threshold models (Damgaard and Korsgaard, 2006; Kärkkäinen and Sillanpää, 2013; Rodovalho et al., 2014) using the different variants of Markov chain Monte Carlo (MCMC) procedures. The benefits and drawbacks of using Bayesian procedures have been emphasized by Blasco (2001) and Cappa and Cantet (2006). In 
summary, the main advantage of the Bayesian approach is the use of a priori information in the analysis, which is particularly important when data are scarce. In fact, the classic estimation of variance components using the restricted maximum likelihood (REML) method may be affected by the absence of observations in any trait and individual; therefore, an alternative to REML estimation is a fully Bayesian approach through MCMC (Cappa and Cantet, 2006). Bayesian analysis also provides additional results to those obtained by the classical method, especially the Bayesian credible intervals for estimates of genetic parameters.

Consequently, the evaluation of a germplasm collection of $F$. chiloensis is necessary in breeding and conservation programs for this species. Moreover, $F$. chiloensis can also be useful for the improvement of commercial strawberries, since several efforts have been made for the reconstruction of $F$. Xananassa using selected genotypes of $F$. chiloensis and Fragaria virginiana (Hancock et al., 2010; Luby et al., 2008). Several wild and domesticated Chilean clones of $F$. chiloensis have been collected and characterized (Carrasco et al., 2007; Del Pozo and Lavín, 2005; Lavín et al., 2005); unfortunately, these germplasm collections are no longer available (Finn et al., 2013). A new germplasm collection of $F$. chiloensis is therefore necessary for breeding and conservation purposes.

The aim of this study was to genetically analyze a new germplasm collection of $F$. chiloensis consisting of wild and domesticated clones from south-central Chile. The analysis included the determination of genetic parameters (broad- and narrow-sense heritability, genetic correlations, additive and dominance variances, and genotypic effects) of survival, flowering, fruit set, and ripening in clones of $F$. chiloensis, to select and identify superior genotypes in the heterogeneous population of the germplasm collection. The novelty of our study is the research of the genetic controls underlying key traits in the chilean strawberry and the genetic evaluation of clones by Bayesian threshold analysis. The useful results obtained from genetic parameters and gains from selection should be useful for the start of a smallscale breeding program of this species in Chile.

\section{Materials and Methods}

Trial location and Plant material. The experiment was conducted in Concepción, Biobío Region, Chile (lat. 36 50' S; long. $73^{\circ} 01^{\prime} \mathrm{W}$; altitude $\left.40 \mathrm{~m}\right)$. The climate is Mediterranean with a maritime influence from the Pacific Ocean. The annual average rainfall is $1110 \mathrm{~mm}$. In winter during the coldest month of July, the mean temperature is $5.7^{\circ} \mathrm{C}$, whereas in summer, the hottest month is January with a mean temperature of $22.8^{\circ} \mathrm{C}$ (University of Chile, 2015). The clonal trial evaluated in this study consisted of 63 clones of chilean strawberry (Supplemental Table 1), of which 55 were wild ( $F$. chiloensis ssp. chiloensis f. patagonica) and 8 domesticated (F. chiloensis ssp. chiloensis f. chiloensis). Wild clones were collected in different natural environments of south-central Chile (lat. $35^{\circ} 05^{\prime} \mathrm{S}$ to $45^{\circ} 17^{\prime} \mathrm{S}$; coastal beaches, Andes mountain range, Nahuelbuta mountain range, lakes, native forests, among others) while domesticated clones were collected from small commercial fields, which are clonally propagated by growers. The domesticated clones were all white fruited, whereas the wild clones were both red and white fruited. Regarding the plants sex, all plants belonging to the $F$. chiloensis were hermaphroditic while plants belonging to the Fragaria patagonica were both female and hermaphroditic. Plants were arranged in a single experiment based on a completely randomized design, with variable replications per clone ( 3 to 40 ramets) in an unbalanced form. This arrangement also facilitated pollination and helped to compensate for the unbalanced pollen production from plants in the germplasm collection.

Growing CONDITIONS AND TRAIT MEASUREMENTS. All plants were maintained in homogenous conditions in a nursery. Plants were grown in a peatmoss: compost $(6: 4 \mathrm{v} / \mathrm{v}) \mathrm{mix}$ at $0.3 \times 0.2-\mathrm{m}$ spacing. Weeds were manually controlled, and fertilization of plants was performed with the administration of: biostimulant (Rukam ${ }^{\circledR}$ Mix; Mabruk AG Comercial y Tecnología, Santiago, Chile), flower fertilizer (Roots ${ }^{\circledR}$; Comercial VOS S.A., Santiago, Chile), and a biostimulant supplement (Phyllum ${ }^{\circledR}$; Anasac Chile S.A., Santiago, Chile) during spring and summer according to manufacturer instructions. Strawberry aphid (Chaetosiphon fragaefolii) and two-spotted spider mite (Tetranychus urticae) along with fungal infections were controlled under appearance, with commercial products. The antifungal treatment was based on $0.2 \%(\mathrm{v} / \mathrm{v})$ benomyl plus $0.2 \%(\mathrm{v} / \mathrm{v})$ captan. Supplemental irrigation was applied once per week during winter and two to three times per week during summer. As a result of severe fungal infection and disease pressure from a variety of pathogens, ramets were evaluated on the basis of plant survival.

The plants ( $\mathrm{N}=796$ ramets) were evaluated for survival (V), flowering $(\mathrm{F})$, fruit set $(\mathrm{S})$, and ripening $(\mathrm{R})$ during the period 2013-14 in different timings: F was evaluated between weeks 8 and 16 after planting, $\mathrm{S}$ and $\mathrm{R}$ (depending on the clone) were studied between weeks 16 and 24 and all clones at 6 months after planting were evaluated for $\mathrm{V}$. $\mathrm{V}$ was recorded as a binary response, in which $0=$ dead and $1=$ alive. $\mathrm{F}, \mathrm{S}$, and $\mathrm{R}$ were determined in this clonal trial by assessing ramets for presence (1) or absence (0) of flower buds, fruit set, and ripe fruit, respectively.

Statistical AND Genetic ANALyses. A Bayesian variance component estimation model was employed to assess clonal responses using the Gibbs sampling algorithm, a variant of the MCMC method, as implemented in the likelihood-based threshold version of Multiple Trait Gibbs Sampler for Animal Models (MTGSAM) (Van Tassell et al., 1998). Threshold models were fitted to phenotypic data, which were considered discrete variables with binary outcomes (Mora and Serra, 2014). Under the threshold model, an observation reflects an underlying unobserved continuous phenotype [liability $(\lambda)$ ], which is assumed to be normally distributed. In matrix notation, the threshold model can be written as:

$$
\lambda=\mathbf{X} \beta+\mathbf{Z}_{1} \mathbf{a}+\mathbf{Z}_{2} \mathbf{d}+\varepsilon
$$

where $\lambda$ is the vector of liability for the binary trait under evaluation; $\mathbf{X}, \mathbf{Z}_{1}$, and $\mathbf{Z}_{2}$ are known incidence matrices; $\beta$ is the vector of the overall mean experiment; $\mathbf{a}$ is a vector of additive genetic effects of genotypes; $\mathbf{d}$ is the vector of dominance effects; and $\varepsilon$ is the residual or within-plot error. The liability $\lambda$ is such that the observed binary responses $\left[\mathrm{y}=\left(y_{i}\right)\right]$ is the result of the relationship (Kadarmideen and Janss, 2005):

$$
y_{i}= \begin{cases}0 & \text { if } \lambda_{i} \leq \mathrm{T} \\ 1 & \text { if } \lambda_{i}>\mathrm{T}\end{cases}
$$

where $\mathrm{T}$ is a fixed threshold; $y_{i}=0$ denotes the absence of a determined event (e.g., dead) and $y_{i}=1$ denotes the presence of an event (e.g., live plant), depending on whether their liability, $\lambda_{i}$, exceeded the threshold point, $\mathrm{T}$, for manifestation of a determined event. 
Uniform prior distributions were defined for $\beta$ and thresholds. Liabilities, additive genetic, and dominance effects are assumed to be normally distributed. On the liability scale, residual effects are assumed to be normally distributed (Van Tassell et al., 1998). The inverted Wishart distribution was used to model the variance-covariance matrixes $\left(\mathbf{G}_{0}, \mathbf{P}_{0}\right.$, and $\left.\mathbf{R}_{0}\right)$ in a bitrait threshold model (Cappa and Varona, 2013; Mora and Saavedra, 2012):

$$
\begin{aligned}
{\left[\begin{array}{l}
\lambda_{1} \\
\lambda_{\mathbf{2}}
\end{array}\right]=} & {\left[\begin{array}{cc}
\mathbf{X}_{1} & \emptyset \\
\emptyset & \mathbf{X}_{2}
\end{array}\right]\left[\begin{array}{l}
\beta_{1} \\
\beta_{2}
\end{array}\right]+\left[\begin{array}{cc}
\mathbf{Z}_{11} & \emptyset \\
\emptyset & \mathbf{Z}_{12}
\end{array}\right]\left[\begin{array}{l}
\mathbf{a}_{1} \\
\mathbf{a}_{2}
\end{array}\right] } \\
& +\left[\begin{array}{cc}
\mathbf{Z}_{21} & \emptyset \\
\emptyset & \mathbf{Z}_{22}
\end{array}\right]\left[\begin{array}{l}
\mathbf{d}_{1} \\
\mathbf{d}_{2}
\end{array}\right]+\left[\begin{array}{l}
\varepsilon_{1} \\
\varepsilon_{2}
\end{array}\right]
\end{aligned}
$$

where $\beta_{1}$ and $\beta_{2}$ are vectors of the overall mean experiment for the traits 1 and 2, respectively; $\mathbf{a}_{1}$ and $\mathbf{a}_{2}$ are vectors of additive genetic effects of genotypes, for the traits 1 and 2, respectively; $\mathbf{d}_{1}$ and $\mathbf{d}_{2}$ are vectors of dominance effects for the traits 1 and 2 , respectively; and $\boldsymbol{\varepsilon}_{1}$ and $\boldsymbol{\varepsilon}_{2}$ are the residuals for the traits 1 and 2, respectively. In a single-trait case: variance $(\mathbf{a})=\mathbf{G}=\mathbf{A} \sigma_{\mathrm{a}}^{2}$, variance $(\mathbf{d})=\mathbf{D}=\mathbf{I} \sigma_{\mathrm{d}}^{2}$, and variance $(\boldsymbol{\varepsilon})=\mathbf{R}=\mathbf{I} \sigma_{\mathrm{e}}^{2}$, where $\mathbf{A}$ is the additive genetic relationship matrix, $\mathbf{I}$ is an identity matrix with dimension equal to number of records, and $\sigma_{\mathrm{a}}^{2}, \sigma_{\mathrm{d}}^{2}$, and $\sigma_{\mathrm{e}}^{2}$ are the additive genetic, dominance, and residual variances, respectively. The genetic relationship between clones was assumed nonexistent (due to the geographical distance at which they were collected), and therefore no effect of inbreeding was considered in the model for genetic evaluation. For the bitrait analysis, we have the following (co)variance matrix estimates:

$$
\begin{aligned}
& \hat{\mathbf{G}}=\hat{\mathbf{G}}_{\mathbf{0}} \otimes \mathbf{A}, \text { in which } \hat{\mathbf{G}}_{\mathbf{0}}=\left[\begin{array}{cc}
\hat{\sigma}_{\mathrm{a}_{1}}^{2} & \hat{\sigma}_{\mathrm{a}_{1} \mathrm{a}_{2}} \\
\hat{\sigma}_{\mathrm{a}_{1} \mathrm{a}_{2}} & \hat{\sigma}_{\mathrm{a}_{2}}^{2}
\end{array}\right], \\
& \hat{\mathbf{D}}=\hat{\mathbf{D}}_{\mathbf{0}} \otimes \mathbf{I}, \text { in which } \hat{\mathbf{D}}_{\mathbf{0}}=\left[\begin{array}{cc}
\hat{\sigma}_{\mathrm{d}_{1}}^{2} & \hat{\sigma}_{\mathrm{d}_{1} \mathrm{~d}_{2}} \\
\hat{\sigma}_{\mathrm{d}_{1} \mathrm{~d}_{2}} & \hat{\sigma}_{\mathrm{d}_{2}}^{2}
\end{array}\right],
\end{aligned}
$$

where the symbol $\otimes$ denotes a Kronecker product operator. Error variances were assumed to be heterogeneous between two traits. The synthesized a posteriori distribution is:

$$
\begin{aligned}
& f\left(\beta, \mathbf{a}, \mathbf{d}, \mathbf{G}_{\mathbf{0}} \otimes \mathbf{A}, \mathbf{D}_{\mathbf{0}} \otimes \mathbf{I}, \mathbf{R}_{\mathbf{0}} \otimes \mathbf{I} \mid \lambda, q_{\mathrm{a}}, \mathbf{G}^{*}, q_{\mathrm{d}}, \mathbf{D}^{*}, q_{\mathrm{e}}, \mathbf{R}^{*}\right) \propto \\
& f\left(\mathbf{y} \mid \boldsymbol{\beta}, \mathbf{a}, \mathbf{d}, \mathbf{G}_{\mathbf{0}} \otimes \mathbf{A}, \mathbf{D}_{\mathbf{0}} \otimes \mathbf{I}\right) \cdot f\left(\mathbf{G}_{\mathbf{0}} / \mathbf{G}^{*}, q_{\mathrm{a}}\right) \cdot f\left(\mathbf{D}_{\mathbf{0}} / \mathbf{D}^{*}, q_{\mathrm{d}}\right) \cdot \\
& f\left(\mathbf{R}_{\mathbf{0}} / \mathbf{R}^{*}, q_{\mathrm{e}}\right) \cdot f(\boldsymbol{\beta}) \cdot f\left(\mathbf{a} \mid \mathbf{G}_{\mathbf{0}} \otimes \mathbf{A}\right) \cdot f\left(\mathbf{d} \mid \mathbf{D}_{\mathbf{0}} \otimes \mathbf{I}\right)
\end{aligned}
$$

where $q_{\mathrm{a}}, q_{\mathrm{d}}$, and $q_{\mathrm{e}}$ are the $\mathrm{df}$ of the distributions, equivalent to degrees of belief; $\mathbf{G}^{*}, \mathbf{D}^{*}$, and $\mathbf{R}^{*}$ are the matrices of scale parameters Convergence of the Gibbs chain was checked using the Heidelberger-Welch test, available at the Coda library of the R program, version 2.6.2 (R Development Core Team, 2011).

Posterior estimates for the narrow $\left(\hat{h}_{\mathrm{a}}^{2}\right)$ and broad-sense $\left(\hat{H}^{2}\right)$ heritabilities were calculated from posterior samples of variance components obtained by the bitrait threshold models detailed above, using the expressions:

$$
\hat{h}_{\mathrm{a}}^{2}=\frac{\hat{\sigma}_{\mathrm{a}}^{2}}{\hat{\sigma}_{\mathrm{a}}^{2}+\hat{\sigma}_{\mathrm{d}}^{2}+\hat{\sigma}_{\varepsilon}^{2}}, \text { and } \hat{H}^{2}=\frac{\hat{\sigma}_{\mathrm{a}}^{2}+\hat{\sigma}_{\mathrm{d}}^{2}}{\hat{\sigma}_{\mathrm{a}}^{2}+\hat{\sigma}_{\mathrm{d}}^{2}+\sigma_{\varepsilon}^{2}}
$$

where $\hat{\sigma}_{a}^{2}, \hat{\sigma}_{d}^{2}$, and $\hat{\sigma}_{\varepsilon}^{2}$ are the additive genetic, dominance, and residual variances. The numerator $\hat{\sigma}_{\mathrm{a}}^{2}+\hat{\sigma}_{\mathrm{d}}^{2}$ denotes the genotypic variance $\left(\hat{\sigma}_{\mathrm{G}}^{2}\right)$. Genotypic correlation between each pair of traits, measured in the same ramet, was calculated by:

$$
r=\frac{\hat{\sigma}_{\mathrm{G}_{X Y}}}{\sqrt{\hat{\sigma}_{\mathrm{G}_{X}}^{2} \cdot \hat{\sigma}_{\mathrm{G}_{Y}}^{2}}}
$$

with $\hat{\sigma}_{\mathrm{G}_{X Y}}$ corresponding to posterior distribution samples of genotypic covariance between each pair of traits, $X$ and $Y$; $\hat{\sigma}_{\mathrm{G}_{X}}^{2}$ and $\hat{\sigma}_{\mathrm{G}_{Y}}^{2}$ are posterior distribution samples of genotypic variance (posterior mean) for the pair of traits in analysis. Clonal genetic gains (CGG) for selection of $\approx 25.4 \%$ of the best clones (i.e., $\mathrm{N}=16$ ) were estimated as follows:

$$
\operatorname{CGG}(\%)=\left[\left(\hat{\mu}_{\mathrm{s}}-\hat{\mu}_{\mathrm{g}}\right) / y_{\mathrm{p}}\right] \times 100
$$

\begin{tabular}{|c|c|c|c|c|c|}
\hline \multirow[b]{2}{*}{ Trait/estimates $^{z}$} & \multirow[b]{2}{*}{ Mean } & \multirow[b]{2}{*}{ Median } & \multirow[b]{2}{*}{ Mode $^{y}$} & \multicolumn{2}{|c|}{$90 \%$ credible sets } \\
\hline & & & & Lower & Upper \\
\hline \multicolumn{6}{|l|}{$\bar{V}$} \\
\hline$\hat{\sigma}_{a}^{2}$ & 0.02 & 0.02 & 0.02 & 0.01 & 0.04 \\
\hline$\hat{\sigma}_{d}^{2}$ & 0.01 & 0.01 & 0.01 & 0.01 & 0.03 \\
\hline$\hat{\sigma}_{\varepsilon}^{2}$ & 0.21 & 0.21 & 0.21 & 0.19 & 0.23 \\
\hline$\hat{h}_{\mathrm{a}}^{2}$ & 0.08 & 0.08 & 0.08 & 0.01 & 0.16 \\
\hline$\hat{H}^{2}$ & 0.14 & 0.13 & 0.13 & 0.08 & 0.21 \\
\hline \multicolumn{6}{|l|}{$F$} \\
\hline$\hat{\sigma}_{\mathrm{a}}^{2}$ & 0.03 & 0.03 & 0.03 & 0.01 & 0.06 \\
\hline$\hat{\sigma}_{d}^{2}$ & 0.02 & 0.02 & 0.01 & 0.01 & 0.05 \\
\hline$\hat{\sigma}_{\varepsilon}^{2}$ & 0.16 & 0.16 & 0.15 & 0.14 & 0.17 \\
\hline$\hat{h}_{\mathrm{a}}^{2}$ & 0.14 & 0.15 & 0.15 & 0.05 & 0.27 \\
\hline$\hat{H}^{2}$ & 0.24 & 0.24 & 0.24 & 0.16 & 0.32 \\
\hline \multicolumn{6}{|l|}{$S$} \\
\hline$\hat{\sigma}_{a}^{2}$ & 0.04 & 0.04 & 0.02 & 0.01 & 0.10 \\
\hline$\hat{\sigma}_{\mathrm{d}}^{a}$ & 0.06 & 0.06 & 0.06 & 0.01 & 0.11 \\
\hline$\hat{\sigma}_{\varepsilon}^{2}$ & 0.15 & 0.15 & 0.15 & 0.13 & 0.17 \\
\hline$\hat{h}_{\mathrm{a}}^{2}$ & 0.17 & 0.15 & 0.07 & 0.04 & 0.37 \\
\hline$\hat{H}^{2}$ & 0.40 & 0.40 & 0.40 & 0.30 & 0.50 \\
\hline \multicolumn{6}{|l|}{$R$} \\
\hline$\hat{\sigma}_{a}^{2}$ & 0.05 & 0.04 & 0.02 & 0.01 & 0.10 \\
\hline$\hat{\sigma}_{\mathrm{d}}^{2}$ & 0.04 & 0.03 & 0.01 & 0.01 & 0.09 \\
\hline$\hat{\sigma}_{\varepsilon}^{2}$ & 0.16 & 0.16 & 0.16 & 0.14 & 0.19 \\
\hline$\hat{h}_{\mathrm{a}}^{2}$ & 0.18 & 0.17 & 0.07 & 0.04 & 0.37 \\
\hline$\hat{H}^{2}$ & 0.33 & 0.32 & 0.31 & 0.21 & 0.46 \\
\hline
\end{tabular}

where $\hat{\mu}_{\mathrm{s}}$ is the estimated posterior mean of the genotypic values of selected clones, $\hat{\mu}_{\mathrm{g}}$ is the estimated posterior population mean of the genotype values of all clones, and $y_{\mathrm{p}}$ is the phenotype mean value for each trait.

Table 1. Marginal posterior point estimates and lower and upper cutoffs for $90 \%$ credible sets from Bayesian threshold model for variance components and heritabilities of survival $(V)$, flowering $(F)$, fruit set $(S)$, and ripening $(R)$ evaluated in 63 clones of the germplasm collection of Fragaria chiloensis.

${ }^{\mathrm{z}} \hat{\sigma}_{\mathrm{a}}^{2}=$ additive variance; $\hat{\sigma}_{\mathrm{d}}^{2}=$ dominance variance; $\hat{\sigma}_{\varepsilon}^{2}=$ residual variances; $\hat{h}_{\mathrm{a}}^{2}=$ narrow-sense heritability; $\hat{H}^{2}=$ broad-sense heritability.

${ }^{y}$ Kernel density estimates of the mode from marginal posterior distributions. 


\section{Results and Discussion}

Goodness-OF-Fit diAgnostics for Bayesian MODEls. The Gibbs chains achieved convergence for variance components using a burn-in of 10,000 iterations and a total of 110,000 Gibbs sampling rounds; 2000 samples were retrieved to estimate marginal posterior distributions. Bayesian estimates of the variance components, narrow and broad-sense heritabilities (with $90 \%$ credible sets) are shown in Table 1. Significant additive variation was observed for all traits under study, according to $90 \%$ credible sets (this interval does not contain the value of zero; Table 1). The additive variance is due to the average or additive effect of a gene or genes, commonly known as the breeding value in plant and animal breeding.

Heritability estimates. Total average values (binary scale, $0-1)$ for the traits under study were $V=0.44, F=0.71, S=0.53$, and $R=0.65$. According to the Bayesian analysis, the traits under study were found to be weakly to moderately heritable, ranging from $14 \%$ for $V$ to $40 \%$ for $S$ (Table 1). Clone 'Manzanar' (MAN) had the highest survival rate $(85 \%)$, followed by the wild clones 'Lleuque' (LLE), 'Lican-Ray' (LIC), 'Santa Barbara' (BAR), and 'Alto Bio Bio' (ALT) and the domesticated clone 'Huaro' (HUA), with $\approx 70 \%$ of survival rate. Several clones (15/63) survived poorly with a rate lower than $20 \%$. Eleven clones had $0 \%$ survival, including the domesticated clone 'Curepto' (CUR) (data not shown). One important reason for the low survival of some clones can be attributed to the low sanitary status of most plants. Aphids and mites were easily controlled, but fungal infections proved to be more difficult. Many of the collected clones had severe damage in the roots and crowns caused by fungi, which can be explained by a low efficiency of the antifungal treatment. These severe infections ultimately caused the death of many ramets of clones, until the different diseases could be controlled in the surviving ramets. This also allowed us to evaluate the response to these infections in terms of survival to fungal infection from the collected clones. Within this context, domesticated clones are grown under poor agricultural practices that increase both the rate and intensity of infection (Rojas et al., 2012), being infected by fungi from the genus Pythium and by Phytophthora
A



C

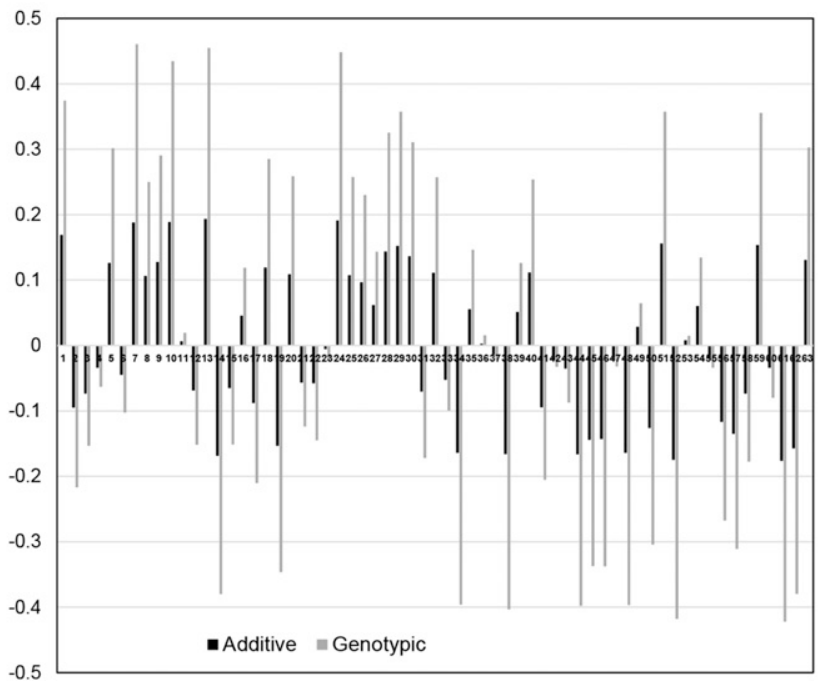

B

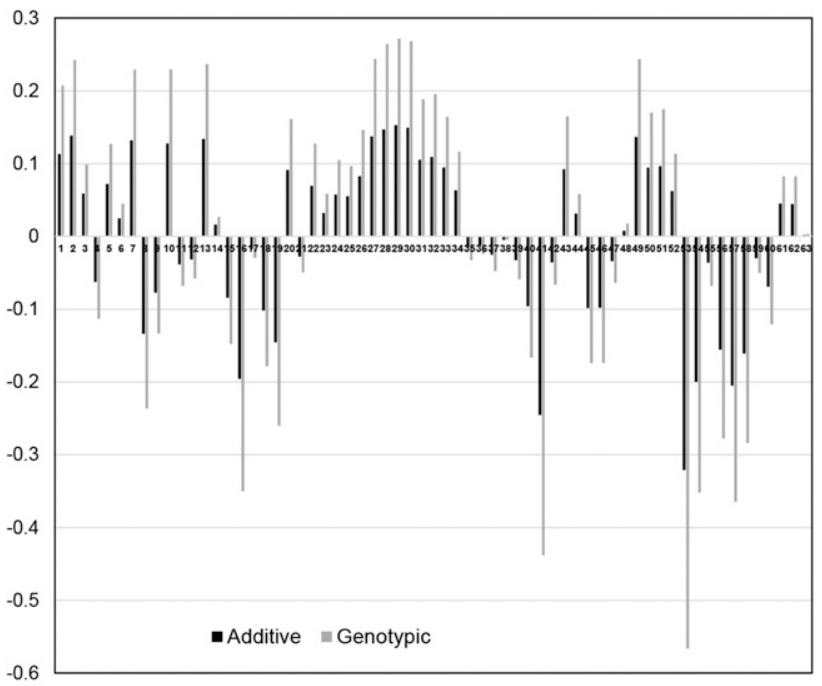

D

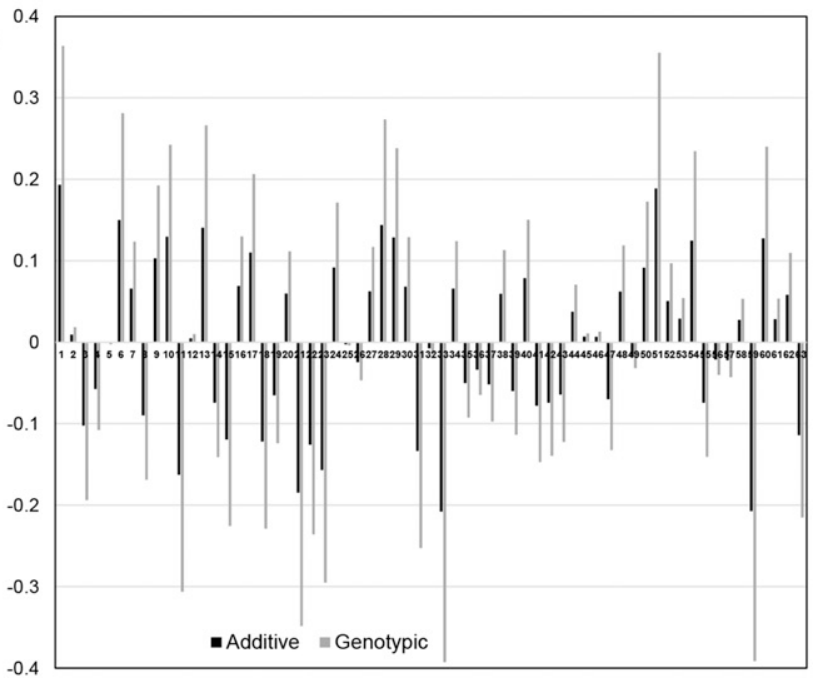

Fig. 1. Additive and genotypic effects in each trait predicted by Bayesian threshold models for 63 clones of the germplasm collection of Fragaria chiloensis. Traits evaluated were (A) survival, (B) flowering, $(\mathbf{C})$ fruit set, and (D) ripening. 
Table 2. Estimates of clonal genetic gains from selection exclusively for survival $(V)$, flowering $(F)$, fruit set $(S)$, and ripening $(R)$ evaluated in 63 clones of the germplasm collection of Fragaria chiloensis. Selection rate was $25.4 \%$ ( 16 clones).

\begin{tabular}{lcccc}
\hline & $V$ & $F$ & $S$ & $R$ \\
\hline Clonal genetic gain (\%) & 17.9 & 21.9 & 34.9 & 22.8 \\
Phenotypic range (\%) & $58-85$ & $90-100$ & $78-100$ & $69-100$ \\
Selected wild clones (no.) & 14 & 13 & 12 & 14 \\
Selected domesticated clones $^{\mathrm{y}}$ & MAN, HUA & MAN, HUA, CNT & MAN, HUA, MAN-2, CHA \\
\hline
\end{tabular}

${ }^{\mathrm{z}}$ For details about clone names see Supplemental Table 2.

${ }^{y} \mathrm{MAN}=$ 'Manzanar'; HUA = 'Huaro'; CNT = 'Contulmo'; MAN-2 = 'Manzanar 2'; CHA = 'Chanco'.

cactorum, which damages the roots and crown, respectively. On the other hand, most of the wild clones were also infected in the crown and roots, probably from P. cactorum and Phytophthora fragariae along with Verticillium albo-atrum. Fungal pathogens of both domesticated and wild clones causing crown and root diseases have been found to infect $F$. ×ananassa (Fang et al., 2011; Kirschbaum and Hancock, 2000). It is noteworthy that screening for disease resistance in $F$. chiloensis, using the fungal pathogens aforementioned, could be a necessary step to associate survival with a specific genetic cause. In this sense, the diversity of fungal pathogens involved is likely partially responsible for the low heritability estimate for survival. Future breeding work focusing on the most important one or two disease-causing pathogens is a reasonable strategy to improve plant survival because heritability of resistance to individual pathogens is probable to be higher.

Growth response, productivity, and fruit quality often garner the majority of attention in the cultivated strawberry (Atkinson et al., 2006; Cocco et al., 2010; Kadir et al., 2006; ZorrillaFontanesi et al., 2012), but survival is another important selection criterion, especially with respect to local adaptation (Shokaeva, 2008). Clones having low survival in a particular geographic area would not be economically viable in intensive crop farming.

The traits under study varied widely among the different clones, and these results agree with those reported by Ashman (1999) in F. virginiana, where broad-sense heritabilities of floral traits were moderately heritable. The relatively high variability observed among genotypes of $F$. chiloensis is also consistent with Dziadczyk et al. (2015) in Fragaria vesca and $F$. Xananassa. Additionally, Mishra et al. (2015) reported the existence of wide ranges of variation among cultivated strawberry genotypes for most of the traits studied, including number of flowers per plant, and various fruit quality traits, which provides opportunities for genetic gain through selection or hybridization. Whitaker et al. (2012) also documented broad phenotypic variation in a strawberry breeding population for fruit and vegetative traits; broad-sense heritability ranged from 0.18 to 0.53 for fruit quality traits. These results indicate that our findings are comparable to those reported for other species of Fragaria.

GENOTYPIC EFFECTS AND CLONAL SELECTION RESPONSE. Additive and genotypic effects, predicted for each clone by Bayesian threshold models, are presented in Fig. 1. These graphs give a general indication on clonal performance in the trial. In this case, positive effects indicate superiority and negative values indicate clones with a lower performance than the experimental average for a determined trait. Thirty-eight, 33, 29, and 32 clones had positive performance for $V, F, S$, and $R$, respectively. Based on genotypic effects with $25.4 \%$ of selection rate, the estimates of CGG are shown in Table 2. Fruit set had the highest
Table 3. Bayesian estimates of genotypic correlations between pairs of traits with $90 \%$ credible sets evaluated in 63 clones of the germplasm collection of Fragaria chiloensis.

\begin{tabular}{lcccrc}
\hline $\begin{array}{l}\text { Genotypic } \\
\text { correlation }^{z}\end{array}$ & Mean & Median & Mode $^{\mathrm{y}}$ & Lower & Upper \\
\hline$V-F$ & 0.244 & 0.258 & 0.255 & 0.000 & 0.569 \\
$V-S$ & 0.084 & 0.000 & 0.002 & -0.224 & 0.406 \\
$V-R$ & 0.425 & 0.447 & 0.496 & 0.000 & 0.771 \\
$F-S$ & 0.427 & 0.440 & 0.461 & 0.149 & 0.676 \\
$F-R$ & 0.332 & 0.354 & 0.424 & 0.000 & 0.676 \\
$S-R$ & 0.538 & 0.560 & 0.630 & 0.169 & 0.803
\end{tabular}

${ }^{\mathrm{z}} V=$ survival; $F=$ flowering; $S=$ fruit set; $R=$ ripening.

${ }^{\mathrm{y}}$ Kernel density estimates of the mode from marginal posterior distributions.

CGG with $\approx 35 \%$, and survival had the lowest value of CGG $(\approx 18 \%)$, which agrees with the highest and lowest values of broad-sense heritability (Table 1), respectively.

The list of the selected clones is shown in Supplemental Table 2. Nine clones displayed a full flowering event (100\% of ramets), of which eight were wild ['Chaiguao' (CHL), 'Cucao-2' (CUC-2), 'Huerquehue 4' (HUE-4), LIC, 'MamuilMalal' (MAM), 'Mañihuales' (MAÑ), 'Nahuelbuta' (NAH), and 'Valdivia' (VAL)] and only one was domesticated ['Contulmo' (CNT)]. On the other hand, the wild clone 'Pinuno' (PIN) was the only clone that did not display flowering events. Fifteen clones (all wild) (15/58) did not set fruit, but the wild clones HUE, LIC, MAM, and the domesticated clone 'Manzanar 2' (MAN-2) did set fruit on all ramets, evidencing a wide variability for this trait in the field experiment. Seven clones achieved ripening in all ramets, six of which were wild ['3 Esteros' (3ST), 'Balmaceda' (BAL), 'Mañihuales 2' (MAÑ-2), 'Molinos' (MOL), 'Petrohué' (PET), and 'Valdivia-2' (VAL-2)], and only one was domesticated (HUA). On the other hand, ten clones did not achieve ripening, of which two were domesticated (CNT and MAN-2). Differences in rate of flowering and flower type had an important role in fruit set. Rate of flowering was the most limiting factor for all the clones, whereas plant sex was important only for a few, since some female clones had a very high rate of flowering and fruit set (data not shown). Another possibility for the low fruit set in some plants would be self-incompatibility. We noted that several accessions had fruit set problems when they were self-pollinated or pollinated with pollen of geographically related plants, but not when pollen from distant accessions was used. This phenomenon has been reported in other species of Fragaria (Bošković et al., 2010; Staudt, 1989).

GeNeTIC CORRELATION ESTIMATES. The Bayesian estimates of genotypic correlations between pairs of traits are shown in Table 3. As expected, $S$ was positively correlated to the 

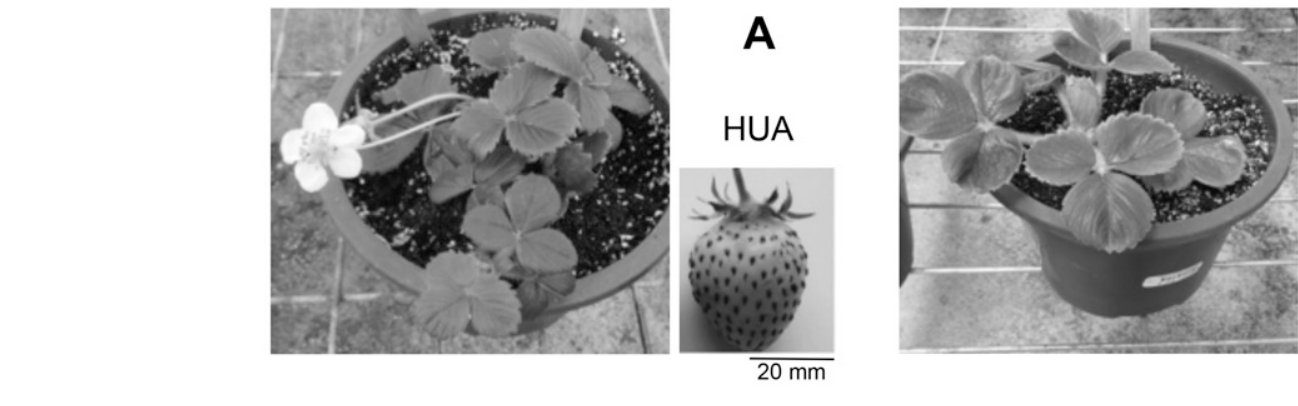

B
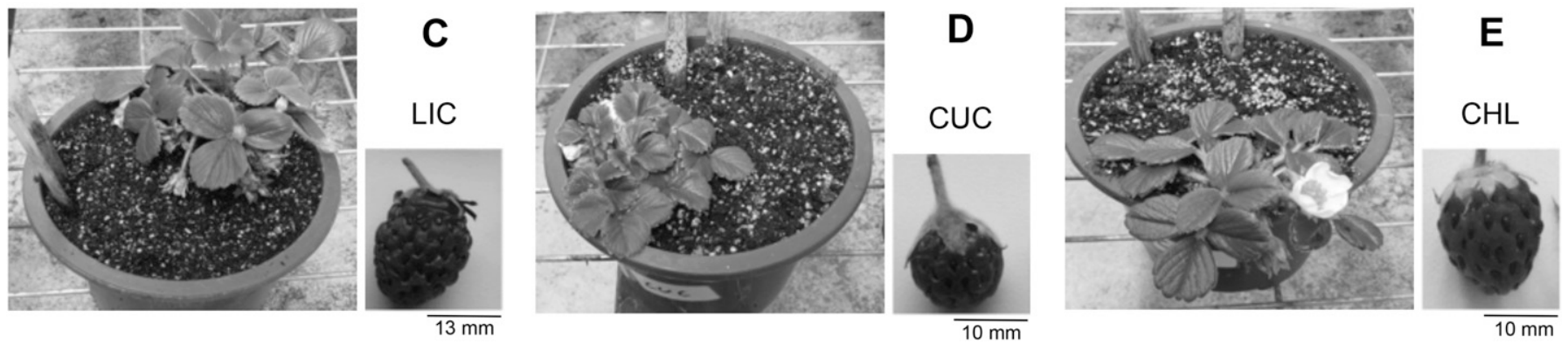

Fig. 2. Representative individuals and fruits for the clones of Fragaria chiloensis belonging to the germplasm collection that were concomitantly selected for survival, flowering, fruit set, and ripening. (A and B) the domesticated clones 'Huaro' (HUA) and 'Manzanar' (MAN), respectively. (C-E) the wild clones 'LicanRay' (LIC), 'Cucao' (CUC), and 'Chaiguao' (CHL), respectively. For details about clones see Supplemental Table 1.

$R$ variable, as indicated by genetic correlations ranging from 0.17 to $0.80(90 \%$ credible set). Eleven clones $(11 / 16)$ were concomitantly selected in both traits. On the other hand, survival had a weak positive genotypic correlation with the other traits under evaluation; in fact, these correlations were not different from zero, as assessed by the $90 \%$ Bayesian credible sets. A genetic correlation not significantly different from zero would indicate that selecting clones based on survival alone would not have a significant effect on the other traits evaluated. However, five of sixteen clones were concomitantly selected for all traits studied: the domesticated clones MAN and HUA, and the wild clones LIC, 'Cucao' (CUC), and CHL (Fig. 2; Supplemental Table 2). It is important to note that the two botanical forms of $F$. chiloensis ssp. chiloensis had positive correlation values between fruit set and ripening, as described (Hancock et al., 2003). In $F$. ×ananassa, Whitaker et al. (2012) found notable negative genetic correlations between fruit traits with several additive and genotypic correlations close to zero indicating independence of the genetic control of the traits studied (e.g., early marketable yield and total misshapen fruit). Mishra et al. (2015) found that fruit yield was significantly and positively associated with most of the 17 morphological and biochemical traits studied, except number of leaves per plant, titratable acidity, and ascorbic acid at both genotypic and phenotypic levels, concluding that selection may be possible for these characters for improving yield. Notably, Whitaker et al. (2012) also mentioned that genetic parameters, such as heritability and genetic correlations, are specific to environments and comparisons to other studies are made only to gain an appreciation for the potential genetic variation for the trait.

Potential for Selective breeding of $\boldsymbol{F}$. Chiloensis. The traits studied here, by a Bayesian approach, were partially heritable with most of them moderately heritable. Plant mortality was a severe problem for several $F$. chiloensis clones, mainly due to the low sanitary status of some clones. Nevertheless, clone survival was found to be weakly heritable, and was not genetically correlated with the other traits, indicating that selection for this trait alone would have little impact on flowering, fruit set, and ripening. Moreover, a selected set of five wild and domesticated clones (Fig. 2; Supplemental Table 2) performed well in all traits studied, indicating that combined selection is possible. The present preliminary study demonstrated that these chilean strawberry selections could have useful yield potential in southern Chile.

\section{Literature Cited}

Ashman, T.L. 1999. Quantitative genetics of floral traits in a gynodioecious wild strawberry Fragaria virginiana: Implications for the independent evolution of female and hermaphrodite floral phenotypes. Heredity 83:733-741.

Atkinson, C.J., P.A.A. Dodds, Y.Y. Ford, J. Le Mière, J.M. Taylor, P.S. Blake, and N. Paul. 2006. Effects of cultivar, fruit number and reflected photosynthetically active radiation on Fragaria $\times$ ananassa productivity and fruit ellagic acid and ascorbic acid concentrations. Ann. Bot. 97:429-441.

Ballesta, P., F. Mora, E. Ruiz, and R. Contreras-Soto. 2015. Markertrait associations for survival, growth, and flowering components in Eucalyptus cladocalyx under arid conditions. Biol. Plant. 59:389-392.

Blasco, A. 2001. The Bayesian controversy in animal breeding. J. Anim. Sci. 79:2023-2046.

Bošković, R.I., J.S. Daniel, and K.R. Tobutt. 2010. Genetic evidence that two independent S-loci control RNase-based self-incompatibility in diploid strawberry. J. Expt. Bot. 61:755-763.

Cappa, E.P. and R.J.C. Cantet. 2006. Bayesian inference for normal multiple-trait individual-tree models with missing records via full conjugate Gibbs. Can. J. For. Res. 36:1276-1285.

Cappa, E.P. and L. Varona. 2013. An assessor-specific Bayesian multithreshold mixed model for analyzing ordered categorical traits in tree breeding. Tree Genet. Genomes 9:1423-1434.

Carrasco, B., M. Garcés, P. Rojas, G. Saud, R. Herrera, J.B. Retamales, and P.D.S. Caligari. 2007. The chilean strawberry [Fragaria chiloensis (L.) Duch.]: Genetic diversity and structure. J. Amer. Soc. Hort. Sci. 132:501-506. 
Cherian, S., C.R. Figueroa, and H. Nair. 2014. 'Movers and shakers' in the regulation of fruit ripening: A cross-dissection of climacteric versus non-climacteric fruit. J. Expt. Bot. 65:4705-4722.

Cocco, C., J.L. Andriolo, L. Erpen, F.L. Cardoso, and G.S. Casagrande. 2010. Development and fruit yield of strawberry plants as affected by crown diameter and plantlet growing period. Pesquisa Agropecu. Bras. 45:730-736.

Coyle, D.R., M.D. Coleman, J.A. Durant, and L.A. Newman. 2006. Survival and growth of 31 Populus clones in South Carolina. Biomass Bioenergy 30:750-758.

Damgaard, L.H. and I.R. Korsgaard. 2006. A bivariate quantitative genetic model for a threshold trait and a survival trait. Genet. Sel. Evol. 38:565-581.

Del Pozo, A. and A. Lavín. 2005. Distribution and ecotypic differentiation of Fragaria chiloensis in Chile. HortScience 40:1635-1636.

Dziadczyk, E., P. Dziadczyk, and M. Tyrka. 2015. Gene pool variation of Fragaria $\times$ ananassa (Duch.) and Fragaria vesca (L.). Acta Sci. Pol. Hortorum Cultus 14:41-50.

Fang, X.L., D. Phillips, H. Li, K. Sivasithamparam, and M.J. Barbetti. 2011. Severity of crown and root diseases of strawberry and associated fungal and oomycte pathogens in Western Australia. Australas. Plant Pathol. 40:109-119.

Finn, C.E., J.B. Retamales, G.A. Lobos, and J.F. Hancock. 2013. The chilean strawberry (Fragaria chiloensis): Over 1000 years of domestication. HortScience 48:418-421.

Hancock, J.F., A. Lavín, and J.B. Retamales. 1999. Our southern strawberry heritage: Fragaria chiloensis of Chile. HortScience 34:814-816.

Hancock, J.F., P.W. Callow, S. Serçe, and P.Q. Son. 2003. Variation in the horticultural characteristics of native Fragaria virginiana and F. chiloensis from North and South America. J. Amer. Soc. Hort. Sci. 128:201-208.

Hancock, J.F., C.E. Finn, J.J. Luby, A. Dale, P.W. Callow, and S. Serçe. 2010. Reconstruction of the strawberry, Fragaria $\times$ ananassa, using genotypes of $F$. virginiana and $F$. chiloensis. HortScience 45:1006-1013.

Kadarmideen, H.N. and L.L.G. Janss. 2005. Evidence of a major gene from Bayesian segregation analyses of liability to osteochondral diseases in pigs. Genetics 171:1195-1206.

Kadir, S., G. Sidhu, and K. Al-Khatib. 2006. Strawberry (Fragaria $\times$ ananassa Duch.) growth and productivity as affected by temperature. HortScience 41:1423-1430.

Kärkkäinen, H.P. and M.J. Sillanpää. 2013. Fast genomic predictions via Bayesian G-BLUP and multilocus models of threshold traits including censored Gaussian data. G3 Genes Genomics Genet. 3:1511-1523.

Kirschbaum, D.S. and J.F. Hancock. 2000. The strawberry industry in South America. HortScience 35:807-811.

Lavín, A., C. Barrera, J.B. Retamales, and M. Maureira. 2005. Morphological and phenological characterization of 52 accessions of Fragaria chiloensis (L.) Duch. HortScience 40:1637-1639.

Luby, J.J., J.F. Hancock, A. Dale, and S. Serçe. 2008. Reconstructing Fragaria $\times$ ananassa utilizing wild $F$. virginiana and $F$. chiloensis: Inheritance of winter injury, photoperiod sensitivity, fruit size, female fertility and disease resistance in hybrid progenies. Euphytica 163:57-65.
Mishra, P.K., R.B. Ram, and N. Kumar. 2015. Genetic variability, heritability, and genetic advance in strawberry (Fragaria $\times$ ananassa Duch.). Turk. J. Agr. For. 39:451-458.

Mora, F. and J. Saavedra. 2012. Combining genetic gain and diversity under an individual selection method in a selected provenance of Eucalyptus cladocalyx. Cienc. Investig. Agrar. 39:177-184.

Mora, F. and N. Serra. 2014. Bayesian estimation of genetic parameters for growth, stem straightness, and survival in Eucalyptus globulus on an Andean foothill site. Tree Genet. Genomes 10:711-719.

Mora, F., F. Tapia, C.A. Scapim, E.N. Martins, R.J.B. Pinto, and A. Ibacache. 2008. Early performance of Olea europaea cv. Arbequina, Picual and Frantoio in the southern Atacama desert. Crop Breed. Appl. Biotechnol. 8:30-38.

R Development Core Team. 2011. R: A language and environment for statistical computing. 1 Aug. 2015. <http://www.R-project.org>.

Retamales, J.B., P.D.S. Caligari, B. Carrasco, and G. Saud. 2005. Current status of the chilean native strawberry [Fragaria chiloensis L. (Duch.)] and the research needs to convert the species into a commercial crop. HortScience 40:1633-1634.

Rodovalho, M., F. Mora, O. Arriagada, C. Maldonado, E. Arnhold, and C.A. Scapim. 2014. Genetic evaluation of popcorn families using a Bayesian approach via the independence chain algorithm. Crop Breed. Appl. Biotechnol. 14:261-265.

Rojas, P., R. Almada, C. Sandoval, K.E. Kellerd, R.R. Martin, and P.D.S. Caligari. 2012. Occurrence of aphidborne viruses in southernmost South American populations of Fragaria chiloensis ssp. chiloensis. Plant Pathol. 62:428-435.

Russo, N.L., T.L. Robinson, G. Fazio, and H.S. Aldwinckle. 2007. Field evaluation of 64 apple rootstocks for orchard performance and fire blight resistance. HortScience 42:1517-1525.

Santos, A.I., R.P. Ribeiro, L. Vargas, F. Mora, L.A. Filho, D.C. Fornari, and S.N. Oliveira. 2011. Bayesian genetic parameters for body weight and survival of Nile tilapia farmed in Brazil. Pesquisa Agropecu. Bras. 46:33-43.

Shokaeva, D.B. 2008. Injuries induced in different strawberry genotypes by winter freeze and their effect on subsequent yield. Plant Breed. 127:197-202.

Sorensen, D., S. Andersen, D. Gianola, and I. Korsgaard. 1994. Bayesian inference in threshold models using Gibbs sampling. Genet. Sel. Evol. 27:229-249.

Staudt, G. 1989. The species of Fragaria their taxonomy and geographical distribution. Acta Hort. (265):23-33.

University of Chile. 2015. Atmósfera, meteorología interactiva. 11 Sept. 2015. <http://www.atmosfera.cl/HTML/climatologia/DATOS/ CHILECENTRO.HTM>.

Van Tassell, C.P., L.D. Van Vleck, and K.E. Gregory. 1998. Bayesian analysis of twinning and ovulation rates using a multiple-trait threshold model and Gibbs sampling. J. Anim. Sci. 76:2048-2061.

Whitaker, V.M., L.F. Osorio, T. Hasing, and S. Gezan. 2012. Estimation of genetic parameters for 12 fruit and vegetative traits in the University of Florida strawberry breeding population. J. Amer. Soc. Hort. Sci. 137:316-324.

Zorrilla-Fontanesi, Y., J.L. Rambla, A. Cabeza, J.J. Medina, J.F. Sánchez-Sevilla, V. Valpuesta, M.A. Botella, A. Granell, and I. Amaya. 2012. Genetic analysis of strawberry fruit aroma and identification of $\mathrm{O}$-methyltransferase FaOMT as the locus controlling natural variation in mesifurane content. Plant Physiol. 159:851-870. 
Supplemental Table 1. Name, geographic location, type, and number of ramets of the different clones of the germplasm collection of Fragaria chiloensis collected in south-central Chile during 2012-13. Clones are listed by latitude in increasing order.

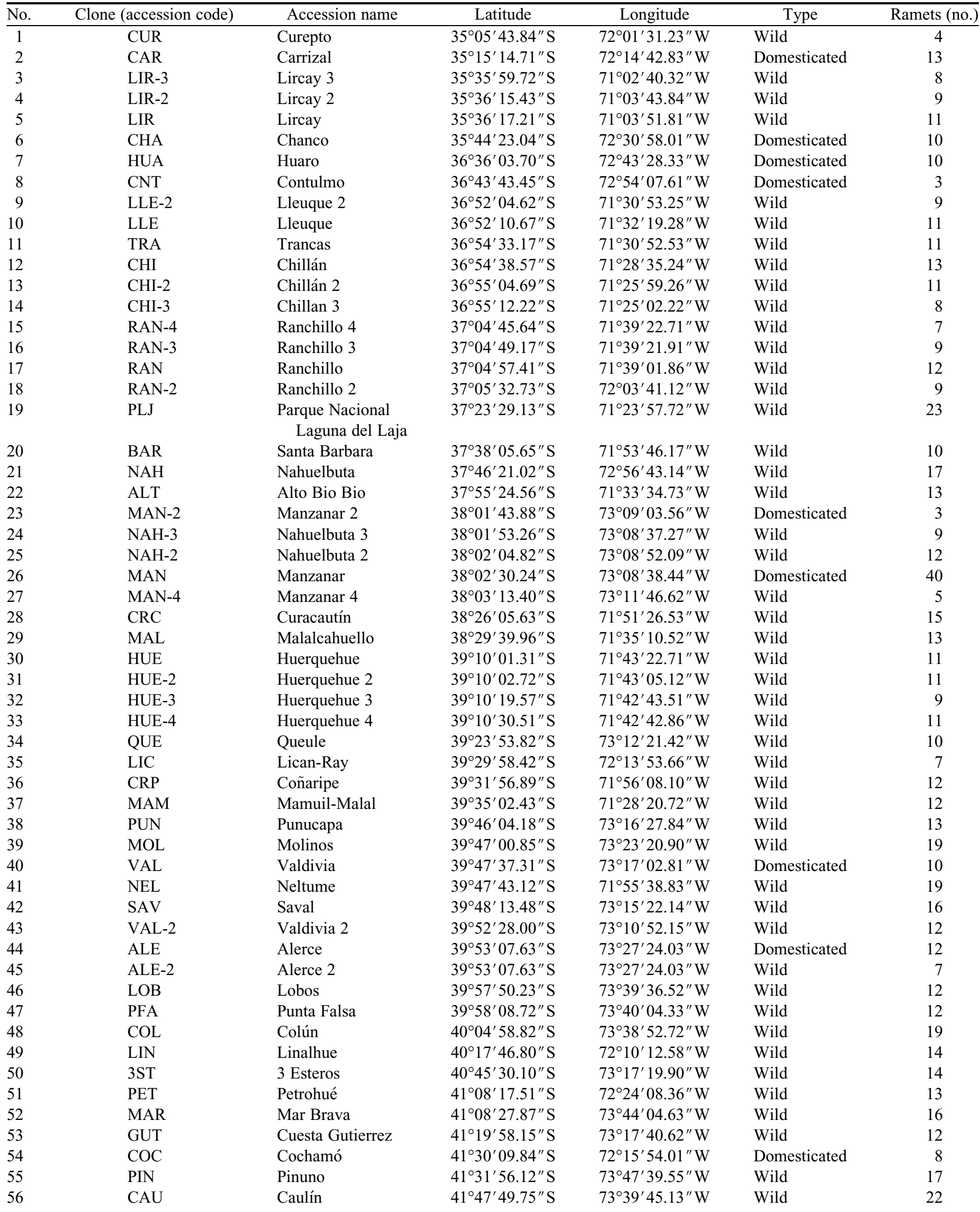


Supplemental Table 1. Continued.

\begin{tabular}{|c|c|c|c|c|c|c|}
\hline No. & Clone (accession code) & Accession name & Latitude & Longitude & Type & Ramets (no.) \\
\hline$\overline{57}$ & CUC & Cucao & $42^{\circ} 35^{\prime} 50.32^{\prime \prime} \mathrm{S}$ & $74^{\circ} 07^{\prime} 26.81^{\prime \prime} \mathrm{W}$ & Wild & 33 \\
\hline 58 & CUC-2 & Cucao 2 & $42^{\circ} 39^{\prime} 30.12^{\prime \prime} \mathrm{S}$ & $74^{\circ} 07^{\prime} 00.87^{\prime \prime} \mathrm{W}$ & Wild & 21 \\
\hline 59 & $\mathrm{CHL}$ & Chaiguao & $43^{\circ} 07^{\prime} 58.92^{\prime \prime} \mathrm{S}$ & $73^{\circ} 30^{\prime} 25.12^{\prime \prime} \mathrm{W}$ & Wild & 16 \\
\hline 61 & MAÑ & Mañihuales & $45^{\circ} 09^{\prime} 49.35^{\prime \prime} \mathrm{S}$ & $72^{\circ} 07^{\prime} 21.11^{\prime \prime} \mathrm{W}$ & Wild & 11 \\
\hline 62 & MAÑ-2 & Mañihuales 2 & $45^{\circ} 13^{\prime} 20.21^{\prime \prime} \mathrm{S}$ & $72^{\circ} 12^{\prime} 52.19^{\prime \prime} \mathrm{W}$ & Wild & 10 \\
\hline 63 & VIS & Vista Hermosa & $45^{\circ} 17^{\prime} 36.00^{\prime \prime} \mathrm{S}$ & $71^{\circ} 44^{\prime} 01.36^{\prime \prime} \mathrm{W}$ & Wild & 15 \\
\hline
\end{tabular}

Supplemental Table 2. List of the Fragaria chiloensis clones ranked for each trait including domesticated and wild clones of the germplasm collection.

\begin{tabular}{|c|c|c|c|c|c|c|c|c|}
\hline \multirow{2}{*}{$\begin{array}{l}\text { Ranking } \\
\text { (no.) }\end{array}$} & \multicolumn{2}{|c|}{ Survival } & \multicolumn{2}{|c|}{ Flowering } & \multicolumn{2}{|c|}{ Fruit set } & \multicolumn{2}{|c|}{ Ripening } \\
\hline & Clone $^{\mathrm{z}}$ & Type $^{y}$ & Clone & Type & Clone & Type & Clone & Type \\
\hline 1 & MAN & $\mathrm{D}$ & CUC-2 & W & MAM & W & MAN & $\mathrm{D}$ \\
\hline 2 & CUC & W & CHL & W & VAL & W & HUA & $\mathrm{D}$ \\
\hline 4 & HUA & $\mathrm{D}$ & HUE-4 & W & LIC & W & CUC & W \\
\hline 5 & ALT & W & MAÑ & W & MAN & $\mathrm{D}$ & VAL & W \\
\hline 6 & BAR & W & $\mathrm{NAH}$ & W & HUA & $\mathrm{D}$ & LIC & W \\
\hline 8 & CRC & W & LIC & W & VIS & W & CUC-2 & W \\
\hline 9 & LOB & W & MAM & W & CUC & W & PET & W \\
\hline 10 & CHL & W & MAN & D & CHL & W & $3 \mathrm{ST}$ & W \\
\hline 11 & MAR & W & $\mathrm{CAU}$ & W & MAN-2 & $\mathrm{D}$ & ALE & W \\
\hline 12 & $\mathrm{ALE}$ & W & GUT & W & MAL & W & MAÑ-2 & W \\
\hline 13 & MAÑ-2 & W & HUA & $\mathrm{D}$ & ALE & W & HUE & W \\
\hline
\end{tabular}

${ }^{\mathrm{z} F o r}$ details about clones see Supplemental Table 1.

${ }^{\mathrm{y}} \mathrm{D}=$ domesticated; $\mathrm{W}=$ wild. 